\title{
Direct measurement of drainage curves in infiltration of SiC particle preforms: influence of interfacial reactivity
}

\author{
J. M. Molina $\cdot$ M. Bahraini $\cdot$ L. Weber $\cdot$ \\ A. Mortensen
}

Received: 18 January 2008/Accepted: 21 April 2008/Published online: 13 May 2008

(C) Springer Science+Business Media, LLC 2008

\begin{abstract}
We present dynamic measurement of drainage curves in two systems having relevance to metal matrix composite processing, namely $\mathrm{SiC} / \mathrm{Al}$ and $\mathrm{SiC} / \mathrm{Al}-$ 12.2at\%Si. Data show that liquid/solid chemical reactions that cause a lowering of the contact angle do indeed drive spontaneous ingress of metal into the preforms at fixed applied pressure; however, these also hinder infiltration under continuous infiltration, lower pressurization rates causing a reduced level of penetration by the metal at given pressure. Metal/reinforcement chemical interactions that can drive wetting by lowering the contact angle are, therefore, not necessarily beneficial in the pressure infiltration processing of particle reinforced metals.
\end{abstract}

\section{Introduction}

It is well known from sessile drop data that wetting in reactive systems is often time-dependent. The underlying reason is that chemical interaction alters the phases and chemical species in presence at the triple line of mutual contact between the melt, the solid, and the atmosphere. As a result the triple line moves under the action of changing capillary forces, at a rate that can be governed either by

J. M. Molina - M. Bahraini - L. Weber · A. Mortensen Laboratory of Mechanical Metallurgy, Institute of Materials, Ecole Polytechnique Fédérale de Lausanne (EPFL),

CH-1015 Lausanne, Switzerland

Present Address:

J. M. Molina ( $\square)$

Dpto. de Física Aplicada, Universidad de Alicante, Apartado 99,

03080 Alicante, Spain

e-mail: jmmj@ua.es local reaction kinetics or by transport of reacting species through the liquid or vapor phases [1-3].

One of the most practically important wetting systems in metal matrix composite material processing is that of solid silicon carbide wetted by aluminum-based melts. This system has been extensively characterized: there are several articles in the literature where sessile drops are used to characterize wetting and its links with reactivity [3-8] for both the $\mathrm{Al} / \mathrm{SiC}$ and $\mathrm{Al}-\mathrm{Si} / \mathrm{SiC}$ systems. It is known that the presence of silicon in aluminum does not significantly modify the wettability of $\mathrm{SiC}[3,5,8]$. It also renders $\mathrm{Al}_{4} \mathrm{C}_{3}$ unstable beyond roughly 11.3at $\% \mathrm{Si}$ at $750{ }^{\circ} \mathrm{C}$, thus preventing carbide formation [9]; however, formation of this compound being slow this generally does not influence the wetting of $\mathrm{SiC}$ [3-5].

A salient feature of $\mathrm{SiC}$ is that below a temperature range that depends on the atmosphere and lies near $1100{ }^{\circ} \mathrm{C}$ in high vacuum, the outer surface of the carbide is constituted of a nanometric layer of $\mathrm{SiO}_{x}(x \leq 2)$ or silicon oxycarbide; above this temperature the $\mathrm{SiC}$ surface is graphitized [3-5]. Below this temperature, therefore, wetting of $\mathrm{SiC}$ is initially akin to wetting of silica and features a high initial contact angle $\left(\theta_{1}\right.$ in the terminology of Ref. [5]), near $110 \pm 10^{\circ}$ for aluminum, both in high vacuum [3-5] or neutral atmospheres [10]. Thereafter, sessile drops spread on the $\mathrm{SiC}$ surface, to gradually attain a lower angle ( $\theta_{2}$ in the terminology of Ref. [5]), either characteristic of wetting of $\mathrm{SiC}$ by the melt and scattered in the range $60 \pm 10^{\circ}$ (depending in particular on the activity of oxygen in the system) [5] or, if alumina formed by reduction of silica coats the $\mathrm{SiC}$ surface, a value near $90^{\circ}$ characteristic of aluminum on alumina [4]. The rate of gradual decrease from $\theta_{1}$ to $\theta_{2}$ is governed by the rate of reduction of the silica layer, to form either alumina plus silicon in solution within the melt or, under high vacuum, the volatile species $\mathrm{Al}_{2} \mathrm{O}$ and $\mathrm{SiO}$, which leave the triple line through the 
atmosphere [5]. Thereafter, the contact angle remains nearly constant.

Depending on the experiment, particularly at lower temperatures and higher oxygen activity in the atmosphere, these stages can be preceded by one of much poorer apparent wetting. This stage is caused by the presence of a film of alumina on the aluminum-based drop [3-5]. In high vacuum this alumina layer evaporates. Data from pressure infiltration experiments show that it also does not interfere with wetting in forced infiltration [11-13]; although there may be oxygen species along the liquid surface in pressure infiltration, data thus show that any thick alumina film at the liquid surface is dynamically skimmed off from the moving molten metal front by the solid preform material, and hence does not interfere with wetting. In pressuredriven infiltration, therefore, this first stage of poor wetting has no importance.

In Ref. [11] we present a study of the wetting of silicon carbide at $750{ }^{\circ} \mathrm{C}$ by $99.99 \%$ pure aluminum and by the aluminum-silicon eutectic ( $\mathrm{Al}-12 \mathrm{at} \% \mathrm{Si}$ ) using a method that differs from the sessile drop experiment. This alternative method is a highly instrumented version of pressure infiltration that measures wetting by means of "drainage" curves. These curves plot, for the system at hand, the capillary pressure that must be applied on the non-wetting metal for it to fill a given fraction of open pore space within a porous preform of the solid phase [14]. What is found for the SiC/Al-Si system is that data are fully consistent with sessile drop data for the wetting of unreacted $\mathrm{SiO}_{2}$ by oxide-free aluminum at that temperature [5]. This makes sense since (i) $\mathrm{SiO}_{2}$ typically covers $\mathrm{SiC}$ and (ii) in these experiments infiltration is forced; as a result the rate of triple line motion is well above the "natural" rate that would be dictated by reaction kinetics. Therefore, the infiltration and the reaction processes are decoupled in time, full coverage of the solid by the liquid occurring well before significant interfacial reaction has taken place.

$\mathrm{The} \mathrm{Al} / \mathrm{SiC}$ and $\mathrm{Al}-12 \mathrm{Si} / \mathrm{SiC}$ systems are, however, prone to two possible interfacial reactions, as detailed in what precedes. One would therefore expect that dynamic wetting effects be observable also in infiltration experiments when the rate of infiltration is sufficiently low for interfacial reaction to take place concomitantly with wetting. In this regime, of rapid reaction and lower rates of infiltration, interaction between the two phenomena is expected. This interaction can, depending on the system, take a variety of forms, reaction in some instances driving metal infiltration (examples are listed in Refs. $[15,16]$ ), or causing in other instances blockage of infiltration if solid reaction products close the pores and "choke" infiltration prematurely, e.g. Refs. [17, 18].

We present here an exploration of the interplay between reaction and wetting during the infiltration of $\mathrm{SiC}$ by $\mathrm{Al}$ and $\mathrm{Al}-12 \% \mathrm{Si}$ using the same experimental approach as in Ref. [11] but conducting experiments under conditions of slower or interrupted pressurization. The results show that chemical reactions that drive wetting in the sessile drop configuration can, in the same system, either aid or hinder wetting during pressure infiltration, depending on conditions.

\section{Experimental procedures}

The infiltration equipment and the setup for the direct measurement of drainage curves are presented in Refs. [11, 14, 19]. This apparatus enables the study of kinetic effects in reactive infiltration since the saturation is tracked dynamically.

In preliminary experiments it was found that dynamic effects are most evident with the finest (F1000) SiC particles; this of course is as expected, given the higher specific surface and smaller diffusion distances. Such particles were thus used, namely black quality SiC F1000 powder with purity $>98 \%$, and $6.5 \mu \mathrm{m}$ of average diameter provided by ESK-SiC-GmbH, Frechen, Germany, identical to those used in Ref. [11]. The $\mathrm{Al}$ and $\mathrm{Al}-12.2$ at\% $\%$ i melts were also the same as in Ref. [11].

The SiC particles were prepared following the same procedure as was used for all infiltrated powder preforms in Ref. [11], namely stirring in $\mathrm{HCl}$ :distilled water $=1: 1$ for $30 \mathrm{~min}$, washing with distilled water, stirring in ethanol for 5 min following by sedimentation and removing the ethanol (repeated three times), and finally drying at $353 \mathrm{~K}\left(80{ }^{\circ} \mathrm{C}\right)$. The $\mathrm{SiC}$ particle surface was thus covered with its native oxide cleaned for metallic impurities by this procedure. XPS analysis of the thus cleaned $\mathrm{SiC}$ particle surface yielded the following surface compositions: $23 \mathrm{wt} \% \mathrm{O}$, 23 wt\% C, 54 wt\% Si (see Table 1 of Ref. [11]).

To evidence reaction-related effects in capillarity during infiltration, two experiments were conducted:

(1) experiments similar to those in Ref. [11], albeit using a lower constant rate of pressurization, namely $0.05 \mathrm{MPa} / \mathrm{s}$ (versus $0.13 \mathrm{MPa} / \mathrm{s}$ in Ref. [11]); and

(2) pressurization was interrupted after a certain amount of metal ingress into the preform at $0.13 \mathrm{MPa} / \mathrm{s}$, so as to detect and monitor spontaneous reaction-driven ingress of metal into the preform.

\section{Results}

Microstructure of the composites

The microstructures of $\mathrm{SiC} \mathrm{F1000} \mathrm{infiltrated} \mathrm{at} 750{ }^{\circ} \mathrm{C}$ to a maximum pressure of $10 \mathrm{MPa}$ with $\mathrm{Al}$ and $\mathrm{Al}-12.2$ at $\% \mathrm{Si}$ 

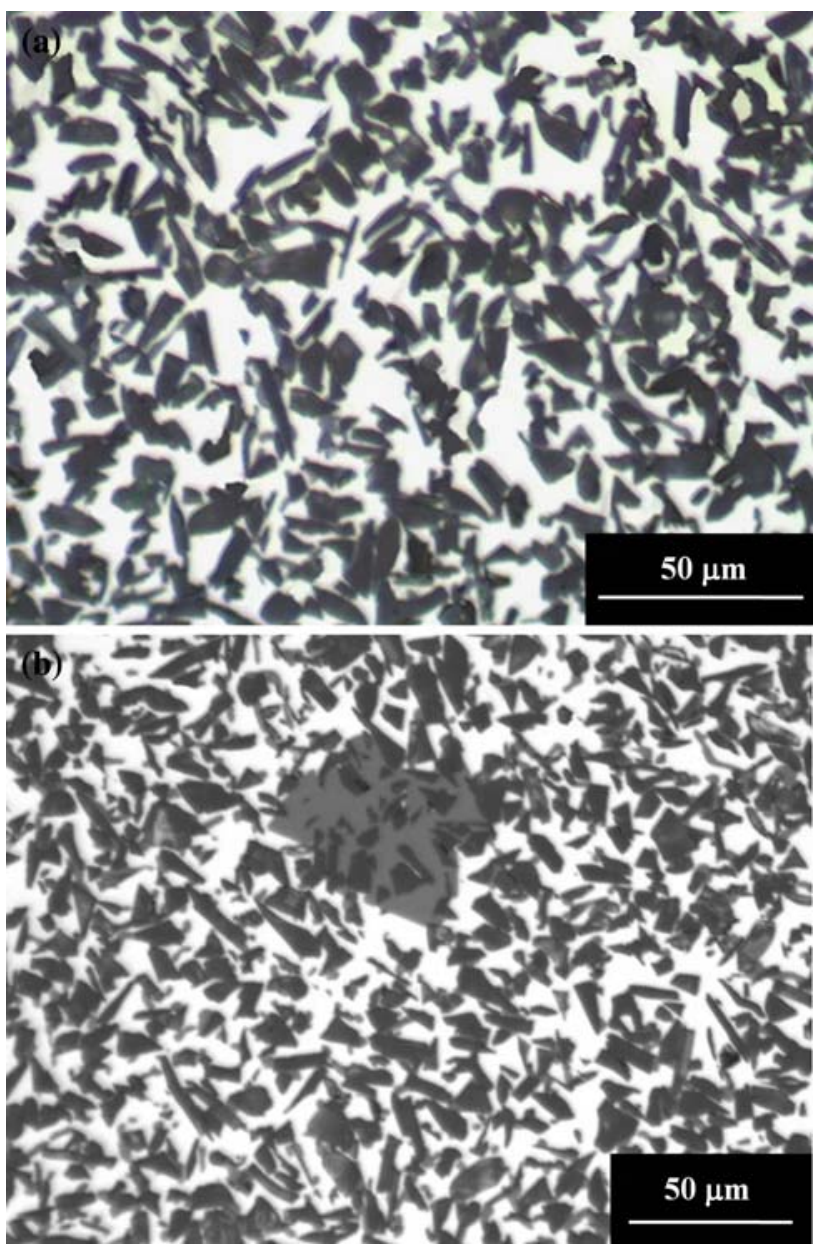

Fig. 1 Optical micrographs of SiC F1000/Al (a) and SiC F1000/ Al-12.2at\%Si (b), infiltrated at $750{ }^{\circ} \mathrm{C}$ and $10 \mathrm{MPa}$. The pressurization rate was $0.13 \mathrm{MPa} / \mathrm{s}$

are shown in Fig. 1a and b, respectively, for the higher pressurization rate of $0.13 \mathrm{MPa} / \mathrm{s}$, and in Fig. $2 \mathrm{a}$ and $\mathrm{b}$, respectively, for the lower pressurization rate of $0.05 \mathrm{MPa} / \mathrm{s}$. At the higher pressurization rate, Fig. 1, full infiltration is achieved, the matrix being free of porosity (see also Figs. 1 and 2 of Ref. [11]). At the lower rate of infiltration, Fig. 2, one notices the presence of dark regions corresponding to residual matrix porosity. These pores, bigger and more frequent with pure aluminum than with $\mathrm{Al}-12.2 \mathrm{at} \% \mathrm{Si}$, have a characteristic length scale of several particle diameters. Figures $1 \mathrm{~b}$ and $2 \mathrm{~b}$ also show, in darker gray color, $\mathrm{Si}$ crystals growing in the matrix, typical of microstructures in solidified eutectic Al-Si alloys.

\section{Drainage curves}

\section{Influence of reduced pressurization rate}

Experiments with $\mathrm{SiC} \mathrm{F} 1000 / \mathrm{Hg}$ at three different pressurization rates were performed (the viscosity of liquid
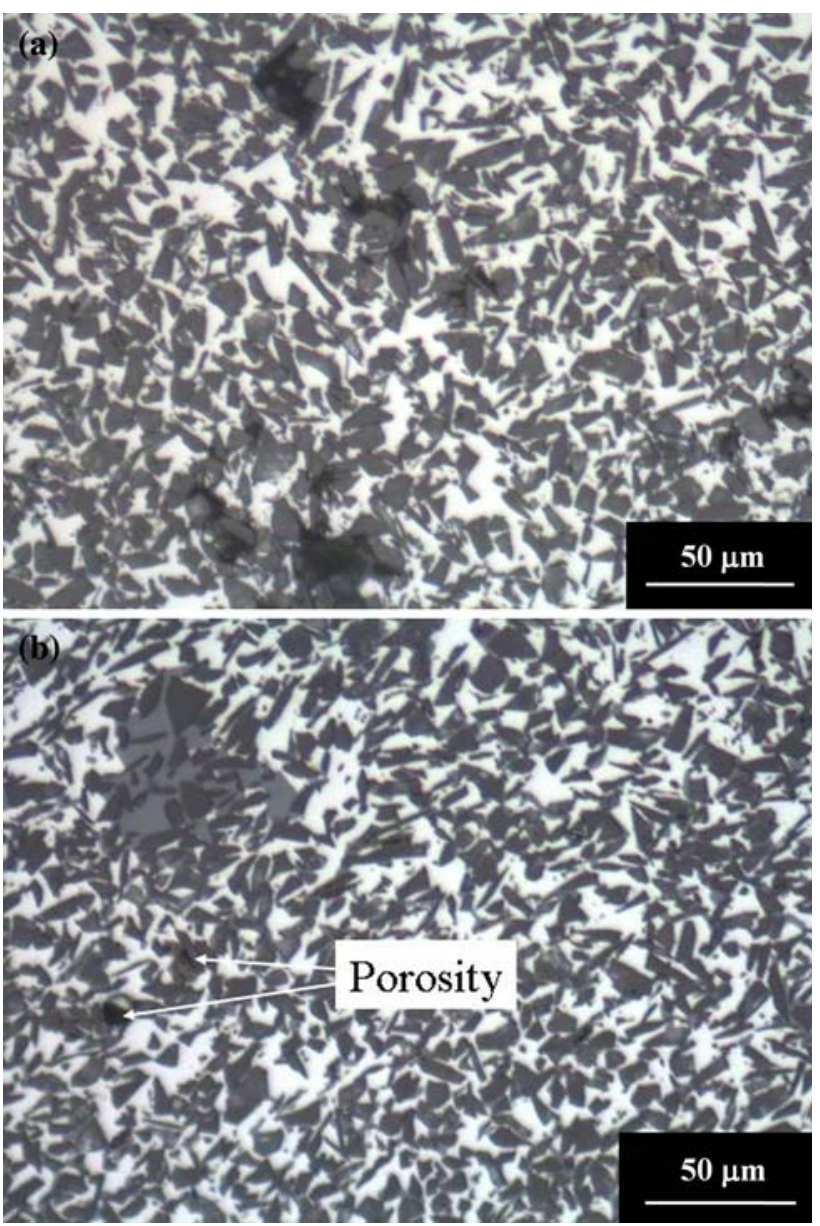

Fig. 2 Optical micrographs of $\mathrm{SiC}$ F1000/Al (a) and SiC F1000/ Al-12.2at\% Si (b), infiltrated at $750{ }^{\circ} \mathrm{C}$ and $10 \mathrm{MPa}$. The pressurization rate was $0.05 \mathrm{MPa} / \mathrm{s}$

mercury at room temperature and liquid aluminum near its melting point are within a factor of two of one another [20]). The three curves superimpose, Fig. 3, showing that (i) the experiment features good reproducibility and (ii) there is no intrinsic influence of pressurization rate in the absence of kinetic effects in wetting. Furthermore, all drainage curves measured with mercury obey the Brooks and Corey correlation, displaying the same pore size distribution index $\lambda$ as curves collected for the same $\mathrm{SiC}$ particles with $\mathrm{Al}$ or $\mathrm{Al}-12 \mathrm{at} \% \mathrm{Si}$ at the higher pressurization rates used in Ref. [11]. This, together with the consistency of data in Ref. [11] with wetting of unreacted $\mathrm{SiO}_{2}$ by the two melts used in this work, shows that the $0.13 \mathrm{MPa} / \mathrm{s}$ data are characteristic of wetting in this system free of the influence of interfacial reactions.

The drainage curves measured upon infiltration of $\mathrm{SiC}$ $\mathrm{F} 1000$ with $\mathrm{Al}$ and $\mathrm{Al}-12 \mathrm{at} \% \mathrm{Si}$ at the reduced pressurization rate of $0.05 \mathrm{MPa} / \mathrm{s}$ are given in Fig. 4 together with the data measured for the same systems at $0.13 \mathrm{MPa} / \mathrm{s}$. It is seen that the shape of the drainage curves is different at the lower pressurization rate. When plotted in the 
appropriate coordinates, the curves measured at $0.05 \mathrm{MPa} / \mathrm{s}$ also depart from the Brooks and Corey correlation that is found to be obeyed by both these systems at the higher pressurization rate and mercury. Furthermore, it is found that, in infiltration with pure aluminum, at the lower pressurization rate full saturation is not attained; rather, the final metal saturation (percent pore space filled with metal) reached a plateau value that densitometric measurements confirmed to be $87 \%$. This agrees with the observed presence of porosity in the composite, Fig. 2a. With the Al-12at\%Si melt nearly full saturation is eventually reached, but whereas the curve gathered at $0.13 \mathrm{MPa} / \mathrm{s}$ reaches full saturation at $4 \mathrm{MPa}$, that measured at $0.05 \mathrm{MPa} / \mathrm{s}$ does not reach a saturation near unity before $10 \mathrm{MPa}$. Metallography indeed shows the presence of only minor porosity at $10 \mathrm{MPa}$ in this system, Fig. $2 \mathrm{~b}$. Results on both systems are in contrast with data in Ref. [11], where with a rate of $0.13 \mathrm{MPa} / \mathrm{s}$ a pore-free matrix results at $10 \mathrm{MPa}$ in this system, Fig. 1.

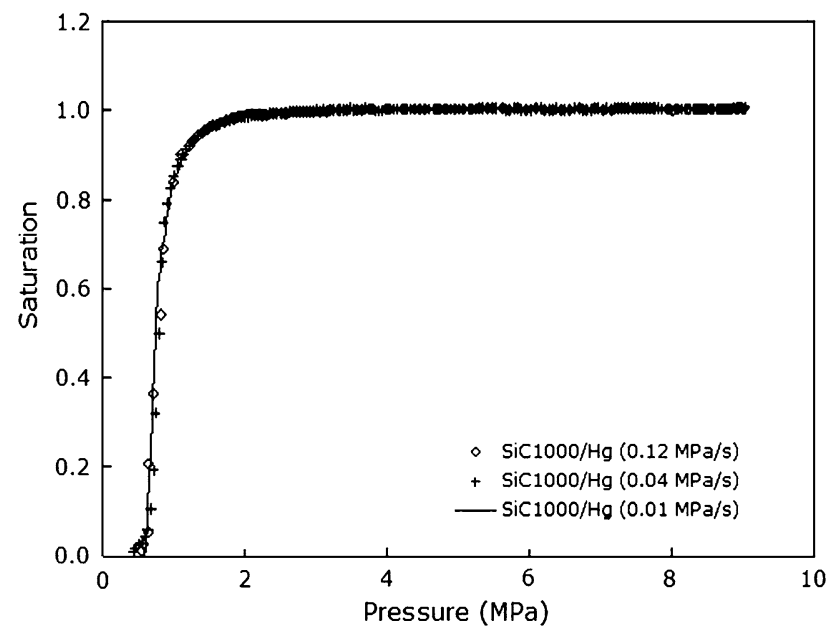

Fig. 3 Drainage curves of $\mathrm{SiC} \mathrm{F} 1000 / \mathrm{Hg}$ at room temperature and in three pressurization rates of $0.01,0.04$, and $0.12 \mathrm{MPa} / \mathrm{s}$

\section{Interrupted pressurization}

The preceding data show that, in both systems, interfacial reaction represents a hindrance during pressure infiltration: for a given pressure, slower infiltration and, hence, more advanced interfacial reaction causes a lowering of the fraction pore space filled with metal. This result is a priori unexpected, since over time, and hence with increasing interfacial chemical interaction, reaction causes a lowering of the contact angle and hence should aid wetting and drive infiltration.

We therefore investigated whether in the absence of a finite rate of pressurization kinetic effects resulting from interfacial reactivity might drive infiltration. To this end, an experiment was started as in Ref. [11] with SiC F1000/Al using a pressurization rate of $0.13 \mathrm{MPa} / \mathrm{s}$, but pressurization was halted at 1.9 $\mathrm{MPa}$, the pressure was held constant for $2 \mathrm{~min}$, and then pressurization was reinstated at the same rate of $0.13 \mathrm{MPa} / \mathrm{s}$; the imposed pressure cycle is given in Fig. 5a. The progressive increase of saturation with time is plotted in Fig. 5b, and in Fig. 5c the saturation/pressure curve resulting from this experiment is superimposed on the $0.13 \mathrm{MPa} / \mathrm{s}$ drainage curve measured for this system.

The aim of this experiment was to track any spontaneous ingress of metal. It is seen that the saturation indeed gradually increases, spontaneously, from a saturation of 0.78 to about 0.9 at the fixed pressure of $1.9 \mathrm{MPa}$, the rate of infiltration decreasing gradually with time. After pressurization is reinstated, the drainage curve first falls below, and then gradually rejoins, the curve obtained under steady pressurization, which is also plotted in Fig. 5c.

\section{Discussion}

The present experiments show that, when the imposed rate of pressurization of the metal is sufficiently low, kinetic effects influence capillarity in infiltration. Furthermore, the
Fig. 4 Comparison of the drainage curves at $750{ }^{\circ} \mathrm{C}$ and $10 \mathrm{MPa}$ of (a) $\mathrm{SiC}$ F1000/Al and (b) SiC F1000/Al-

$12.2 \mathrm{at} \% \mathrm{Si}$, measured at the two pressurization rates of 0.13 and $0.05 \mathrm{MPa} / \mathrm{s}$
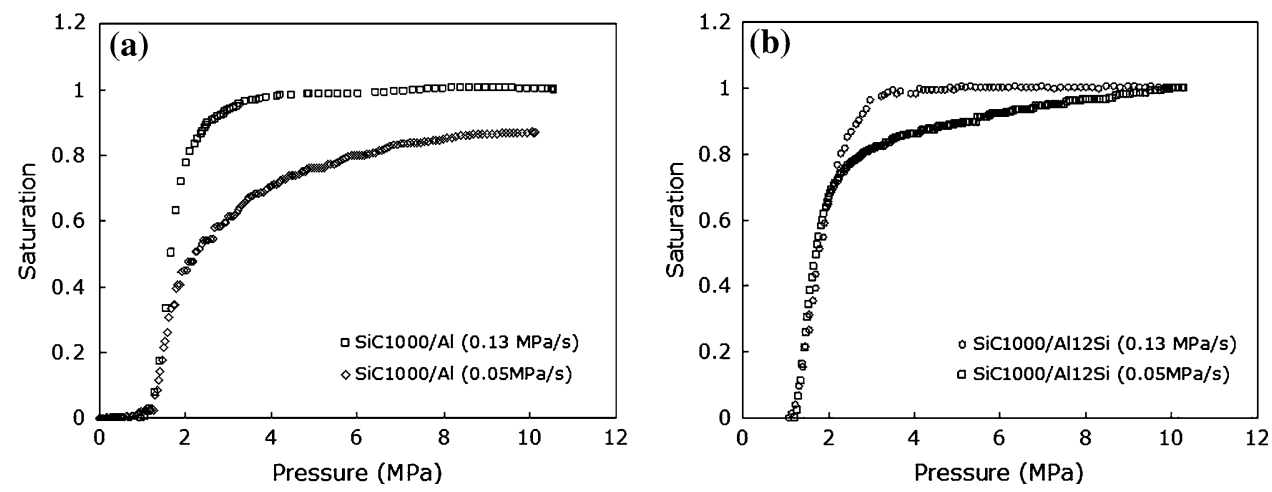
Fig. 5 Pressure-time (a), saturation-time (b), and saturation-pressure (c) curves for $\mathrm{SiC} \mathrm{F1000/Al} \mathrm{at} 750{ }^{\circ} \mathrm{C}$, for an experiment conducted up to a pressure of $10 \mathrm{MPa}$, at $\mathrm{d} P /$ $\mathrm{d} t=0.13 \mathrm{MPa} / \mathrm{s}$ with a $2-\min$ interruption at $1.9 \mathrm{MPa}$ (the arrows in (a) and (b) show the interval of interruption). Plot (c) also gives the drainage curve measured for this system under steady pressurization at $\mathrm{d} P / \mathrm{d} t=0.13 \mathrm{MPa} / \mathrm{s}$
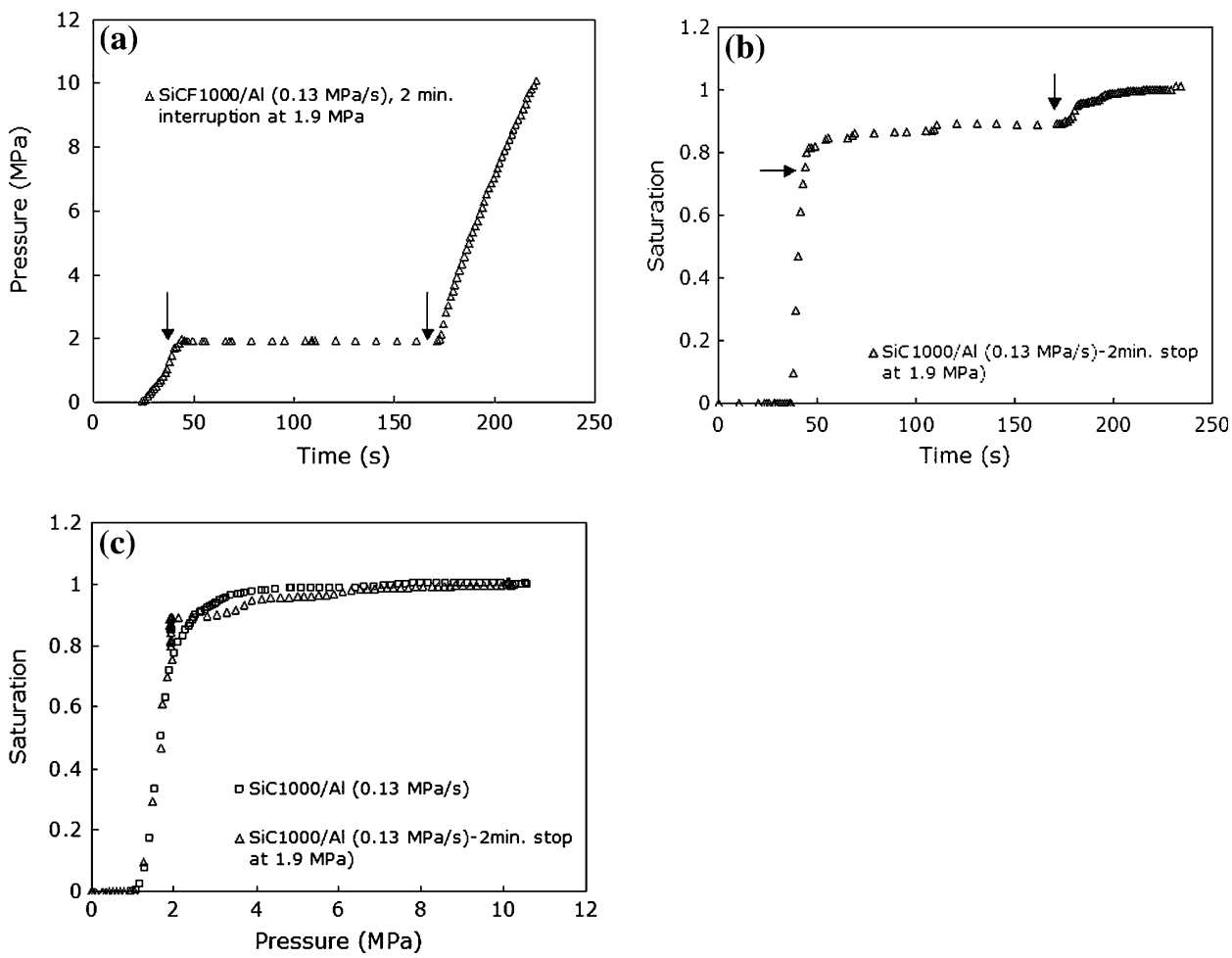

data show that these effects can, in the same system, either impair penetration of the preform (when the pressurization rate is low, at $0.05 \mathrm{MPa} / \mathrm{s}$ in this work) or drive infiltration (when pressurization is stopped).

Before attempting to explain the observed effects, a few remarks about the present experiments are in order.

(1) In both Ref. [11] and the experiments presented here, the pressurization rate was kept sufficiently low so as to maintain viscous pressure losses well below capillary pressures; relevant calculations are given in Ref. [21] and experimental evidence for an absence of significant viscous loss in this regime of infiltration is provided by Fig. 3 for mercury intrusion at three different infiltration rates. Kinetic effects observed here are therefore entirely capillary in origin.

(2) Since silicon in molten aluminum exerts a negligible influence on wetting (as known from sessile drop data in the literature $[3,5,8]$ and confirmed by the data in Ref. [11]), silicon concentration gradients, which might arise in the present infiltration experiments due to interfacial reaction coupled with fluid flow, should be inconsequential. This is a significant simplification of the present system.

(3) A complication, on the other hand, is that the atmosphere influences the kinetics of wetting in this system. Indeed, reported rates of motion of the triple line in sessile drop experiments are for ultrahigh vacuum (total pressure $P \leq 5 \times 10^{-5} \mathrm{~Pa}$ and oxygen partial pressure of about $\left.10^{-15} \mathrm{~Pa}[4,5]\right)$, where the process is governed by the rate of evaporation of volatile oxides $\left(\mathrm{SiO}, \mathrm{Al}_{2} \mathrm{O}\right)$ [3-5]. In the present work, although the oxygen partial pressure measured inside the chamber is very low $\left(10^{-17} \mathrm{~Pa}\right)$, the total residual gas pressure is not better than 0.2 mbar (it is generated by a mechanical pump, and kept by the molten metal sealing the preform from the surrounding atmosphere) [14]. Also, the temperature is somewhat lower, at $750{ }^{\circ} \mathrm{C}$. For these reasons the de-oxidation process is probably not as rapid as in ultrahigh vacuum, such that spontaneous, reactionlimited, triple line velocities in the present system are likely lower than in ultrahigh vacuum sessile drop experiments. Values of triple line velocities taken from the curves in Ref. [4] are near $7 \times 10^{-2} \mu \mathrm{m} / \mathrm{s}$ for $\mathrm{Al}$ on oxidized $\mathrm{SiC}$ at $900{ }^{\circ} \mathrm{C}$ and also for $\mathrm{Al}-19.5 \mathrm{at} \% \mathrm{Si}$ on $\mathrm{SiC}$ at $800{ }^{\circ} \mathrm{C}$, and about $4 \times 10^{-2} \mu \mathrm{m} / \mathrm{s}$ for $\mathrm{Al}$ on $\mathrm{SiC}$ at $800^{\circ} \mathrm{C}$. We thus take $10^{-1}$ to $10^{-2} \mu \mathrm{m} / \mathrm{s}$ as an order of magnitude estimate of the maximum possible value of spontaneous triple line velocities of $\mathrm{Al}$ and Al-Si alloys over $\mathrm{SiC}$ in our experiments.

(4) In the present technique, we measure not the rate of motion of the triple line, but the rate of increase of saturation, i.e., the rate at which the metal volume fraction present within the porous preform increases. The link between this quantity and the triple line velocity depends on the precise infiltration path followed by the metal as it fills open pores within 
the preform. Given the intricate geometry of the ceramic particles, and also the complex morphology of pores found in partially infiltrated samples (see Figs. 1 and 2 of Ref. [19] where this is clearly visible on an analogous but non-reactive system), this infiltration path, and hence the trajectory of the triple line, is very complex.

A lower limit of the total length of this trajectory is obviously the particle radius, of about $3 \mu \mathrm{m}$ (Table 1 of Ref. [11]) - the corresponding infiltration flow path is, then, one of metal gradually filling all meniscuses between contacting particles in the last phases of infiltration. The time to infiltrate, at constant pressure and with a spontaneous triple line velocity of $10^{-1}$ to $10^{-2} \mu \mathrm{m} / \mathrm{s}$, the preform is then on the order of 30-300 s. As seen in Fig. 5, in the present interrupted experiment, the saturation increases from 80 to $90 \%$ in $120 \mathrm{~s}$, which is not out of line with this crude estimate.

This estimate suffers, however, from two limitations. First, triple line velocities characteristic of sessile drop experiments in high vacuum were used; it is, as mentioned earlier, likely that lower velocities than $10^{-1}$ to $10^{-2} \mu \mathrm{m} / \mathrm{s}$ are obtained in the present experimental conditions since lower rates of evaporation of volatile oxides are expected. Secondly, the infiltration path is clearly more complex than was assumed in this simple calculation; in particular, its length is very probably longer than one particle radius since pores present in the later stages of infiltration span several particles (Figs. 1 and 2 of Ref. [19]): the triple line is correspondingly likely to travel distances several times the pore diameter to close off the last pores. To increase the saturation by $10 \%$ in $120 \mathrm{~s}$ as observed here, spontaneous triple line rates of motion must therefore have been, on average, significantly higher than $10^{-1}$ to $10^{-2} \mu \mathrm{m} / \mathrm{s}$.

An assumption that might reconcile these two contradictory conclusions is that the line moves by jumps during spontaneous infiltration. In this scheme, spontaneous spreading serves to overcome local capillary barriers, the metal moving much more rapidly past such localized pinning points under the joint action of capillary forces and the applied pressure. The existence of such jumps, called "Haines jumps," is indeed a well-known feature of capillarity in porous media [22]. With this interpretation, the steadily decreasing rate of spontaneous infiltration at fixed pressure, Fig. 5b, may be explained by the gradual exhaustion of pinning points that can be overcome by reaction-driven triple line motion. We note that, given the observation made in Ref. [11] that the total work spent to force the metal into the preform equals, with relatively good precision, the total thermodynamic work of immersion, these jumps must be accompanied by comparatively little expenditure of irreversible energy, be it capillary or kinetic.

Turning to the influence of pressurization rate, we first note that the total time for infiltration of the preform is, at $0.13 \mathrm{MPa} / \mathrm{s}$, around $70 \mathrm{~s}$. This is on the order of the time estimated for the shortest possible triple line trajectory using upper-bound estimates of the spontaneous triple line velocity. It thus is very likely that the average triple line velocity was, during pressure-infiltration at $0.13 \mathrm{MPa} / \mathrm{s}$, well above the spontaneous reaction-driven triple line velocity. This conclusion in turn agrees with the observation that wetting in infiltration at this rate of pressurization is typical of non-reactive wetting of silica by aluminum, as shown in Ref. [11].

Lowering the pressurization rate from $\mathrm{d} P / \mathrm{d} t=$ $0.13 \mathrm{MPa} / \mathrm{s}$ to $\mathrm{d} P / \mathrm{d} t=0.05 \mathrm{MPa} / \mathrm{s}$ causes a downward shift in the drainage curves, Fig. 4. Thus, while it can cause spontaneous ingress of the metal into the preform, reaction in fact impairs infiltration during pressure infiltration. One possibility is that this effect may result from a change in the kinetics of interaction between wetting and any oxygen in the surrounding gas near the wetting front; such effects are for example found in wetting of alumina by aluminum (see for example [23, 24] and references therein). One would, then, however expect that drainage curves show an equally strong transition in drainage curves with temperature, as temperature too will affect the kinetics of interaction with oxygen. This is not seen, data in all our experiments to date with the present apparatus agreeing with expectations from sessile drop data for conditions where no interference exists between liquid metal surface oxidation and wetting, as indicated in the "Introduction" section.

An alternative explanation for the effect of pressurization rate is that reaction may cause topological changes in the pore shape, narrowing these at "bottlenecks" that govern the flow path under the influence of capillary forces. In the $\mathrm{SiC} / \mathrm{Al}$ system, reaction will first cause aluminum oxide formation by reduction of the silica layer under conditions of slow volatile oxide evaporation, and given sufficient time also platelets of aluminum carbide that extend into the matrix with pure $\mathrm{Al}$ (see Figs. 1 and 2 of Ref. [11]). Both reaction products are not very well wetted by aluminum [3] and, if their shape is complex, their presence will create geometric capillary barriers to infiltration. If reaction is sufficiently extensive, the reaction products may also lower the permeability of infiltrated portions of the preform, causing viscous pressure losses to become noticeable or even choking of metal flow by pore closure.

That the influence of reduced pressurization rate be attributed to the physical presence of reaction products, 
rather than a relation between infiltration rate and intrinsic capillary parameters (the wetting angle and work of immersion), is consistent with data in that (i) in SiC F1000/ Al-12.2at\% Si, where reaction is less pronounced than in SiC F1000/Al (forming only aluminum oxide by reduction of the native oxide layer but not aluminum carbide), the effect be less marked, and (ii) there be a "memory" effect after the $120 \mathrm{~s}$ hold at $2 \mathrm{MPa}$, such that after spontaneous ingress of the metal at fixed pressure, upon further pressurization at $0.13 \mathrm{MPa} / \mathrm{s}$, the rate and extent of metal penetration be less than with similar but uninterrupted pressurization, Fig. 5b.

\section{Conclusions}

- We show that under forced, pressure-driven infiltration, interfacial reactions that cause a gradual lowering of the wetting angle in sessile drop experiments and thus aid wetting, can either aid or hinder infiltration of $\mathrm{SiC}$ preforms by aluminum-based melts. Specifically, while interfacial reactions can cause spontaneous penetration of partially infiltrated metal into the preform at fixed applied pressure, during infiltration driven by a rising applied pressure with negligible viscous pressure losses, interfacial reactions can hinder infiltration.

- It is proposed that these effects are due to the fact that chemical interactions cause, in addition to a lowering of the wetting angle, morphological changes at the solid/ liquid interface, which can hinder wetting and infiltration.

- A corollary is that, from a practical point of view, rapid pressure infiltration is in fact preferable in processing metal matrix composites featuring interfacial reactivity, even when liquid/solid chemical interactions improve wetting in sessile drop experiments.

Acknowledgements The authors gratefully acknowledge financial support of this research from NEDO International Joint Research Grant Program, Project 01MB7, CTI project no. 6752-2 and the internal funds from the Laboratory of Mechanical Metallurgy at EPFL.

\section{References}

1. Eustathopoulos N (1998) Acta Mater 46:2319. doi:10.1016/ S1359-6454(97)00388-1

2. Eustathopoulos N (2005) Curr Opin Solid State Mater Sci 9:152. doi:10.1016/j.cossms.2006.04.004

3. Eustathopoulos N, Nicholas MG, Drevet B (1999) Wettability at high temperatures. Pergamon Press, Oxford, UK

4. Laurent V, Chatain D, Eustathopoulos N (1991) Mater Sci Eng A 135:89. doi:10.1016/0921-5093(91)90542-U

5. Laurent V, Rado C, Eustathopoulos N (1996) Mater Sci Eng A 205:1. doi:10.1016/0921-5093(95)09896-8

6. Naidich JV (1981) Progress in surface and membrane science, vol 14. Academic Press, New York

7. Kölher W (1975) Aluminium 51:443

8. Laurent V, Chatain D, Eustathopoulos N (1987) J Mater Sci 22:244. doi:10.1007/BF01160579

9. Lloyd DJ (1989) Compos Sci Technol 35:159. doi:10.1016/02663538(89)90093-6

10. Shen P, Fujii H, Matsumoto T, Nogi K (2004) Metall Mater Trans A 35:583. doi:10.1007/s11661-004-0369-0

11. Bahraini M, Molina JM, Weber L, Mortensen A (2007) Mater Sci Eng A (accepted)

12. Mortensen A, Wong T (1990) Metall Trans A 21:2257. doi: 10.1007/BF02647888

13. Molina JM, Rodriguez-Guerrero A, Bahraini M, Weber L, Narciso J, Rodriguez-Reinoso F, Louis E, Mortensen A (2007) Scripta Mater 56:991. doi:10.1016/j.scriptamat.2007.01.042

14. Bahraini M, Molina JM, Kida M, Weber L, Narciso J, Mortensen A (2005) Curr Opin Solid State Mater Sci 9:196. doi: 10.1016/j.cossms.2006.02.007

15. Mortensen A, Jin I (1992) Int Mater Rev 37:101

16. Mortensen A (2000) In: Clyne TW (vol ed), Kelly A, Zweben C (series ed) Comprehensive composite materials, vol 3. Metal matrix composites. Pergamon Press, Oxford, UK

17. Chiang YM, Messner RP, Terwilliger CD, Behrendt DR (1991) Mater Sci Eng A 144:63. doi:10.1016/0921-5093(91)90210-E

18. Nakae H, Fujii H, Nakajima K, Goto A (1997) Mater Sci Eng A 223:21. doi:10.1016/S0921-5093(96)10488-3

19. Bahraini M, Weber L, Narciso J, Mortensen A (2005) J Mater Sci 40:2487. doi:10.1007/s10853-005-1980-1

20. Geiger GH, Poirier DR (1973) Transport phenomena in metallurgy. Addison-Wesley, Reading, MA

21. Bahraini M (2007) Characterization of capillary forces during liquid metal infiltration. Phd-thesis, Ecole Polytechnique Fédérale de Lausanne (EPFL), Switzerland

22. Morrow NR (1970) Ind Eng Chem 62:32. doi:10.1021/ie50726 a006

23. Levi G, Kaplan W (2003) Acta Mater 51:2793

24. Levi G, Kaplan W (2002) Acta Mater 50:75. doi:10.1016/S13596454(01)00333-0 